\title{
LA TRAGEDIA Y LA PAIDEÍA DEL DOLOR Y LA LOCURA: HERACLESY ORESTES
}

\author{
Lidia Gambon \\ Universidad Nacional del Sur \\ lgambon@uns.edu.ar
}

Resumen: La tragedia griega asumió como función social y elemento esencial de su paideía una abarcadora reflexión sobre el dolor, escenificando con frecuencia, en el marco de su construcción simbólica, patologías como la locura. El objetivo del presente artículo será precisamente analizar el léxico y la representación del dolor en dos tragedias euripideas: Heracles (c. 416 a. C.) y Orestes (408 a. C.). Ambas exponen la situación marginal de un héroe asesino, víctima de la locura, mostrando coherencia y variedad en la representación del dolor y la enfermedad a partir del modo en que se relacionan el destino del héroe, el ô̂kos y la pólis.

Palabras clave: tragedia, dolor, locura, Heracles, Orestes

\begin{abstract}
Greek tragedy took as an essential element of its paideía a comprehensive reflection on pain, staging often pathologies like madness as part of its symbolic construction. The aim of this paper is to analyze the vocabulary and the representation of pain in two Euripidean tragedies, Heracles (c. 416 BC.) and Orestes (408 BC.). Both plays expose the marginal situation of a murderer hero, victim of madness, showing cohesion and variety in the depiction of pain and disease in relation to the fate of the hero, the ôk os and the pólis.
\end{abstract}

Keywords: tragedy, pain, madness, Heracles, Orestes 
En un ensayo contemporáneo consagrado a la reflexión sobre el dolor, David Morris no solo reconocía a la tragedia griega la capacidad de escudriñar un territorio ignorado por la medicina, sino de formular uno de los más profundos interrogantes de la condición humana: qué hacer con el dolor (Morris, 1994 [1991]). Proponía así — como punto de partida, no como definición - que la tragedia es la forma literaria que asume como función social principal una prolongada y abarcadora reflexión acerca del dolor y el sufrimiento humano. A priori no resulta difícil coincidir con esta perspectiva, no solo porque el uso ordinario del término "trágico" apoya esta mirada, sino porque el lenguaje de la enfermedad y del dolor atraviesa cada una de las piezas dramáticas. La complejidad de las aristas del tema, sin embargo, no debe subestimarse. Integradas a la construcción de un imaginario, las patologías que escenifica la tragedia traspasan el orden de lo físico, para traducir con frecuencia la disfunción orgánica del espacio social cívico y familiar — la pólis y el ổkos—; se proyectan así reiteradamente como una metáfora que "explica" esa disfunción, a través, entre otros recursos, de la presencia ostensiva de un vocabulario nosológico. ${ }^{1}$

Dicho vocabulario nosológico, como el imaginario que acaba por conformar, se sostiene en un presupuesto: el de la

\footnotetext{
${ }^{1}$ Sobre la enfermedad como expresión de la disfunción del orden cívico, remitimos a las contribuciones de Jennifer C. Kosak y de Roger Brock en Death and Disease in the Ancient City (Hope \& Marshall, 2000), y de Roger Brock en Greek Political Imagery from Homer to Aristotle (Brock, 2013, pp. 69-82). En La institución imaginaria del oikos en la tragedia de Eurípides se analiza la enfermedad como expresión de la disfunción del espacio familiar (Cf. Gambon, 2009).
} 
construcción simbólica del drama, aquella que define para la mirada trágica la normalidad a través de la anomalía, el orden funcional a través de la disfunción, la salud a través de la enfermedad. En la representación de las historias del mito, la tragedia está atravesada toda ella por esa visión idiosincrásica que podríamos denominar "patológica". Se trata, sin embargo, y como consecuencia de este mismo carácter simbólico, de una visión sobradamente compleja, que responde y se corresponde con el carácter paidéutico alusivo e indirecto de un género de naturaleza política (i.e. que interpela a la pólis y refiere ínsitamente a ella). Por un lado, y en relación con el dolor y la enfermedad, esta visión entronca - muy especialmente en Eurípides - con el desarrollo de la actividad práctica y especulativa de la misma ciencia médica en la Grecia del s. V a. C., que se ocupa y preocupa de igual modo por restaurar el equilibrio saludable del cuerpo. En tal sentido, medicina y tragedia se constituyen en el período clásico en formas de un discurso centrado en la nosología, y consecuentemente vemos imperar en el teatro no solo diferentes tipos de enfermedades, sino un lenguaje común que "sharpens in intensity and multiplies in frecuency" (Mitchell-Boyask, 2008, p. 4). ${ }^{2}$ Por otro, dicha perspectiva plantea el modo indistinguible, inseparable, en que suelen relacionarse el sentido concreto y metafórico, somático y simbólico de una nósos trágica bajo la imagen del héroe sufriente. Este es un aspecto que, percibido

\footnotetext{
2 Asumimos así que la frecuencia de aparición de términos como nósos se corresponde con la intensidad de la preocupación o la importancia asignada al tema. Esta preocupación es común tanto a la medicina hipocrática (Aguilar, 2002; Schironi, 2010) como al drama (Mitchell-Boyask, 2008).
} 
seguramente de manera natural por los griegos, solo las más recientes investigaciones de lingüística cognitiva han venido a poner de relieve, en particular en el estudio de temas como el dolor y las emociones. ${ }^{3} \mathrm{Y}$ en ningún padecimiento resulta esto tan claro, quizás, como en la locura, donde la interconexión entre mente y cuerpo es manifiesta, y el drama se complace en exhibirla. Así, con frecuencia, el héroe víctima de la manía fluctúa en su enfermedad entre estados emocionales variados en los que se anula la distancia entre síntoma físico y estado mental, y vemos confluir en el discurso trágico de manera indisociable el dolor del cuerpo y de la mente, las emociones y el aspecto moral.

Si a la medicina contemporánea interesaba la naturaleza del sufrimiento y sus causas, la tragedia le otorgó un lugar "pervasivo" al dolor, exponiendo su categoría compleja de semeîon y emoción asociada a la esfera conceptual de la enfermedad. El primero de los aspectos, el que sitúa al dolor en la categoría de signo, guarda una clara conexión con la naturaleza ambigua del síntoma -que la misma medicina hipocrática se esforzaba en interpretar y que la tragedia se complace en explotar-; también con la emergencia del cuerpo como objeto epistémico en el período clásico, recientemente puesta de relieve (Holmes, 2010). La segunda caracterización, la que sitúa al dolor en el lugar de la emoción, a la par que vinculado a ella, guarda relación asimismo con la ciencia $y$,

\footnotetext{
${ }^{3}$ En la medida en que el enfoque cognitivo entiende que la conceptualización del dolor y las emociones es una construcción social, constreñida por lo biológico y al mismo tiempo culturalmente definida por los componentes que cada sociedad selecciona en función de un foco empírico determinado (Cf. Theodoropoulou, 2012).
} 
además, con una de las funciones esenciales del teatro, destinado no solo a representar sino a generar empatía en el dolor (LaCourse Munteanu, 2012).

El objetivo del presente artículo será precisamente analizar el léxico y la representación del dolor en dos tragedias euripideas: Heracles (c. 416 a. C.) y Orestes (408 a. C.). Ambas exponen la situación marginal de un héroe asesino que es víctima de la locura, aun cuando el tormento de la manía se concentra en diferentes momentos del drama. Mientras la locura de Heracles precede a los crímenes familiares, y acarrea sufrimientos que se despliegan sobre todo en la última parte de la pieza, la de Orestes, que no es causa sino consecuencia del asesinato más impío, ocupa la primera parte de la obra. ${ }^{4}$ Heracles define su marginalidad a partir de nuevas hazañas (la muerte de su esposa y de sus hijos) realizadas bajo los alcances de la locura incitada por Lisa; Orestes, en cambio, no ha

${ }^{4}$ La distinción y relación entre cada una de las partes depende naturalmente de cuestiones estructurales en las que no entraremos aquí, pero que, en líneas generales, pueden resumirse en el reconocimiento en ambas tragedias de dos mitades de dimensiones quasi semejantes. En el caso de Heracles, hay coincidencia en señalar un primer momento centrado en la amenaza y la salvación de la familia del héroe (vv. 1814) y un segundo tiempo dramático (vv. 815-1428) que instala la aparición de Lisa y centra el conflicto en la locura (y las consecuencias de la locura de Heracles). En Orestes, es posible advertir un primer momento en que los hijos de Agamenón actúan como víctimas a la espera de la decisión de la asamblea argiva (vv. 1-843), y un segundo momento en que Orestes y Electra son compelidos a obrar como victimarios para procurarse su salvación (vv. 843-1693), aun cuando caben otras posibilidades, como las planteadas por E. García Novo (García Novo, 1981) o M. C. Schamun (Schamun, 1995). Ello no invalida nuestras afirmaciones. Sobre la polémica estructura y unidad dramática de Heracles, pueden consultarse los aportes de E. Griffiths (Griffiths, 2006, pp. 42-64), M. Sanz Morales y M. Librán Moreno (Sanz Morales \& Librán Moreno, 2008, pp. 59-60) y E. Hall (Hall, 2010, p. 166); para la estructura bipartita de Orestes, M. Wright ofrece un análisis (Wright, 2008, pp. 29-50). 
matado a su madre en estado de perturbación mental, pero su situación marginal se potencia en la disrupción del orden familiar y social que representa este crimen, y especialmente en el padecimiento de la manía derivada del acto cometido, lo que problematiza la relación del héroe no solo con su entorno sino consigo mismo (Medda, 2013, pp. 176-177). Por ello, aun cuando sea posible coincidir en un sentido con el juicio de Theodorou acerca de que estos héroes no tienen nada en común, "not even their madness" (Theodorou, 1993, p. 36), nos proponemos mostrar que Eurípides despliega en la pintura del dolor y la locura de estas tragedias de las últimas décadas del siglo un tratamiento que exhibe a la par variedad y cohesión en la presentación de la enfermedad, aunando el destino del héroe, el ổkos y la pólis, y ahondando sobre todo en la sintomatología emocional del dolor de la locura. En tiempos de una convulsionada Atenas, ya desgastada por más de diez años de insensata guerra fratricida ¿de qué otro modo podía interpelarse a la pólis?

\section{Heracles: el héroe del dolor superlativo ${ }^{5}$}

Heracles es una tragedia en la que se hace coincidir de manera dolorosamente paradójica la salvación de la ciudad y la familia con el ataque de locura del héroe, que atrae la completa destrucción del ôkeos, consume la casa en la más absoluta

\footnotetext{
${ }^{5}$ Para las citas del texto griego de las obras analizadas hemos seguido la edición de J. Diggle $(O C T)$. Las traducciones en todos los casos nos pertenecen.
} 
vergüenza (v. 1423-4) y deja a Tebas desolada. Invirtiendo la secuencia de trabajos, Eurípides presenta al inicio del drama a un Heracles que ha debido abandonar en esta ciudad a su esposa Mégara, a sus tres hijos y a su padre mortal Anfitrión, para marchar al Hades y asegurar con esta última labor el pago definitivo a Euristeo por el retorno del exiliado Anfitrión a Argos. Como Orestes al matar a Clitemnestra, Heracles al marcharse dejando solos a los suyos ha actuado movido por las obligaciones que crea la philía parental. Pero la crisis política, bajo la forma de una stásis o sedición, ha enfermado a Tebas

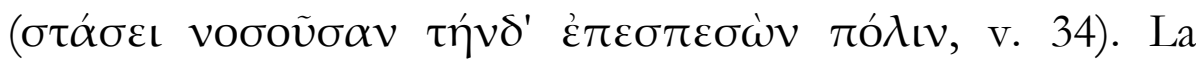
ciudad ya no razona bien (vv. 272-274); y ciudadanos ambiciosos, en su locura, han llevado al poder, durante la ausencia del héroe, a un advenedizo, un tirano. Este no solo ha matado al rey y a sus hijos, sino que amenaza con acabar con toda la familia de Mégara, de modo que el parentesco político con Creonte se ha convertido en un gran mal para Heracles. Gobernada por el tirano Lico, Tebas deviene un espacio completamente hostil para la familia del héroe descendiente de Zeus, y para una casa que carece de phíloi (v. 430). De ahí que el momento del retorno de Heracles, del rescate de la forzosa muerte de los miembros del ôkkos, sea celebrado de manera esperanzada por el coro como una afortunada metabolé ( $\mu \varepsilon \tau \alpha \beta о \lambda \dot{\alpha} \kappa \alpha \kappa \tilde{\omega} v$, v. 735, cf. vv. 765-766). Sin embargo, esta metabolé, que nace con un crimen (la muerte de Lico) para multiplicarse en muchos otros, resulta singularmente dolorosa en razón de la entronización del tema de la locura.

Un rasgo singular del imaginario de esta tragedia es el modo en que la crisis política de Tebas -anti-modelo trágico de la pólis 
(Zeitlin, 1990)- se expresa mediante la imagen de la enfermedad y la locura; Eurípides se sirve para caracterizar el mal de la ciudad de los mismos términos que refieren en el desarrollo del drama al padecimiento del héroe. Así, vooćc

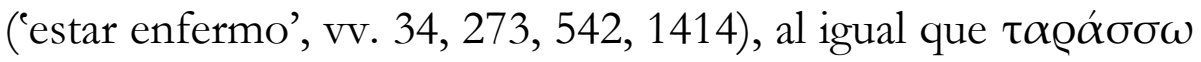
('perturbar') y sus derivados nominales (vv. 533, 605, 836, 908, 1091) se aplican indistintamente a Tebas y a Heracles, estableciendo de este modo explícitamente una conexión entre la salud del héroe y la salud del cuerpo político, aunque este aspecto tan significativo no siempre haya resultado evidente en las lecturas críticas de la obra. ${ }^{6}$

En cuanto a la locura misma, un amplio espectro de familias de palabras concurren en esta tragedia para designarla, designar las acciones que desencadena y el estado de quien la padece: desde $\mu \alpha v i ́ \alpha / \mu \alpha i ́ v o \mu \alpha ı$ ('locura'/estar loco', vv. 835, 878,

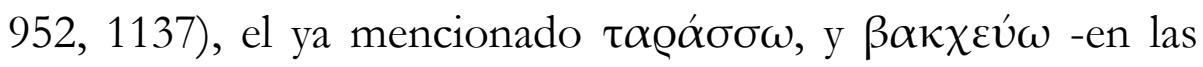
significaciones activa ('inspirar locura') y pasiva ('sufrir locura') de su valor transitivo- (vv. 898, 966, 1086, 1122, 11427), hasta

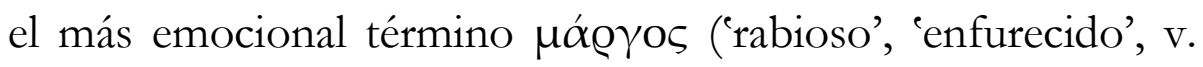
1082, cf. $\mu \alpha \varrho \gamma \alpha ́ \omega$, v. 1005) y el que designa a la misma diosa

\footnotetext{
${ }^{6}$ Esta conexión fue señalada por J. C. Kosak (Kosak, 2004, pp. 151-174) y por R. M. Mitchell-Boyask (Mitchell-Boyask, 2008, p. 124), y puesta recientemente en relación con el valor y los usos del verbo tarásso (Cf. Gambon, 2016).

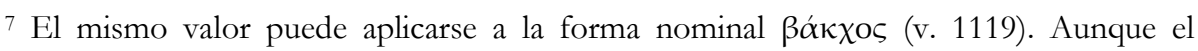
sentido fundamental del verbo $\beta \alpha \kappa \chi \varepsilon v ́ \omega$ refiere a la locura báquica o inspirada por Dioniso, es el valor más general el que prima en Heracles, sea para designar la locura que inspira Lisa, o de la que es víctima Heracles. Como señala H. Perdicoyianni-Paléologou (Perdicoyianni-Paléologou, 2009b), las formas nominales y verbales de esta familia son acuñaciones del período clásico.
}

$N^{\circ}$ 5. Primer Semestre de 2016 
de la locura en la obra, $\lambda u ́ \sigma \sigma \alpha$ (vv. 866, 878, 883, 887, 898, 1024). ${ }^{8}$ La imagen patológica que impera, en virtud de la caracterización de esta diosa y de su aparición en escena, es, por un lado, la que asocia la locura a la conducta bestial y salvaje; 9 por otro, la que entiende la enfermedad como un funcionamiento defectivo, un estado de desorden debido a la alteración del equilibrio o isonomía de los elementos compositivos del cuerpo, y en el caso particular de Heracles (como en el de Orestes), de la mente o phrén ( $\varphi \varrho \varepsilon v \tilde{\omega} v$

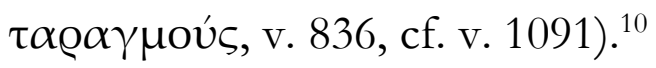

Desde su misma aparición, Iris enfatiza que ella y Lisa no vienen a atacar a la ciudad, sino tan solo la casa de Heracles (vv. 824-825). Reafirma, en el explícito contraste que establece entre ôkkos y pólis, la amenazante relación entre el destino del héroe y su familia. De algún modo Heracles debe pagar las consecuencias de su condición de hijo bastardo de Zeus (vv. 841-842). ${ }^{11}$ Pero el precio exigido -como es de uso en un

\footnotetext{
${ }^{8}$ Un estudio exhaustivo del vocabulario de la locura y su valor en el período clásico es el que brinda H. Perdicoyianni-Paléologou en sus dos artículos (Perdicoyianni-Paléologou, 2009a; 2009b). La personificación de la locura, Lisa, si no llega a ser una innovación completamente euripidea, adquiere sus rasgos idiosincrásicos como personaje dramático con este trágico (Cf. Duchemin, 1967).

${ }^{9}$ Esta imagen patológica guarda relación con la percepción de la enfermedad como invasión de una fuerza externa daimónica (Cf. Padel, 1992, pp. 138-161).

${ }^{10}$ La concepción de la enfermedad como desequilibrio halló sustento científico en la teoría fisiológica de los humores desarrollada por los médicos hipocráticos. La noción de isonomía referida a la salud se remonta al filósofo presocrático Alcmeón de Crotona (s. VI a. C.).

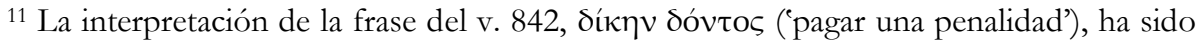
discutida en relación a la responsabilidad de Heracles en su locura. Su valor ambiguo,
} 
género que muestra por esencia la violación extrema de las relaciones de philía (Belfiore, 2000)- es demasiado alto, pues Heracles, enloquecido, mata a sus más queridos phíloi (v. 1147).

Aunque la locura es presentada doblemente en la obra -de manera prospectiva y poética por las diosas (vv. 822-885) ${ }^{12}$, y de manera retrospectiva y más realista por el mensajero (vv. 922-1015)-, y aunque en cada una de ellas se abunda en la sintomatología y las emociones que comporta la manía, en Heracles, a diferencia de Orestes, el ataque en sí es circunscripto al espacio retro-escénico. La centralidad del sufrimiento aparece así confinada no al momento de la manía sino al de la recuperación de la conciencia después de la crisis. Se trata de un proceso gradual, que sucede a una crisis que es temporal (y no recurrente, como en el caso de Orestes), después de la cual Heracles se siente confundido (vv. 1094 ss.), amnésico (vv. 1105-1108) y acusa aún síntomas físicos de su agitada $y$ convulsiva actividad maníaca, como su respiración irregular (v. 1092)..$^{13}$ Apenas recuperado, cree estar de nuevo en el Hades (v. 1101) -y en cierto modo lo está, hallándose entre muertos-;

señalado por E. Griffiths (Griffiths, 2006, pp. 88-90), no oculta la significación del problemático lazo parental de philía de Heracles, en tanto hijo del mortal Anfitrión y del dios Zeus. Sobre todo J. Gregory (Gregory, 1997, pp. 121-154) se ha detenido en el tema de la doble paternidad de Heracles y la relación que mantiene con el sufrimiento del héroe.

12 Autoras como M. G. Ciani (Ciani, 1974, p. 89) y posteriormente A. Guardasole (Guardasole, 2000, p. 197) señalaron la matriz esquílea de esta primera descripción. Remitimos a sus observaciones en lo que refiere a contrastes y similitudes entre una y otra escena, y para los puntos de contacto de la segunda descripción de la locura con los textos médicos.

${ }^{13}$ La misma sensación experimentará Orestes en los vv. 215-216 y 277-279. 
pero no reconoce la geografía, y se siente aturdido, sin recursos (v. 1105). Si la locura ha representado un proceso de extrañamiento, de alienación, por el que Heracles "ya no era el mismo" (vv. 931, 965), la amnesia que le sigue es a su vez un estado no menos saludable de incapacidad de entendimiento

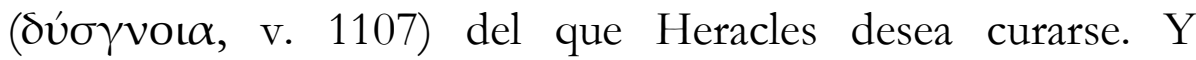
mientras Orestes encuentra en el reconocimiento de lo realizado ( $\sigma u ́ v \varepsilon \sigma \iota \varsigma$, Or. 396) una fuente de dolor y locura que

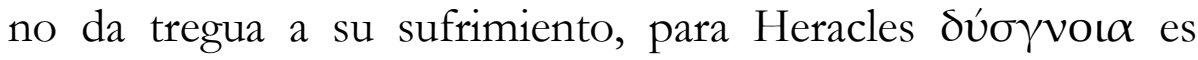
parte de un mal al que desea sobreponerse, pero cuya cura resulta aun peor que la misma enfermedad, por el sufrimiento que entraña.

Si los mismos tratados médicos explotaron el uso de términos polisémicos para referir al dolor, lo que les permitía insistir en la ambigüedad de su estatuto (Villard, 2006), la tragedia lleva la ambigüedad y la polisemia al paroxismo. Tal es lo que sucede con el término tóvos ('trabajo', 'dolor', 'esfuerzo'), que representa una de las grandes familias de palabras de dolor para la medicina, y es uno de los vocablos de mayor presencia en Heracles. ${ }^{14}$ El término, como el verbo derivativo $\pi$ ové $\omega$, refiere en la primera parte de la obra tanto a las hazañas del héroe, entre las que se incluye el rescate de su familia (vv. 22, 388, 427, 575, 1275, 1353, 1410), como a las

\footnotetext{
${ }^{14}$ L. Villard señala đóvoৎ como una de las tres grandes familias de palabras que en los escritos hipocráticos se usan para referir al dolor, y destaca que, a excepción de óoúv

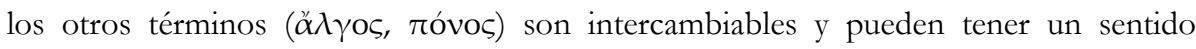
diferente (Villard, 2006, pp. 161-162). Claramente en Heracles Eurípides explota la polivalencia del término al elegir, además, un vocablo distinto del homérico $\alpha$ $\varepsilon \theta \lambda$ o utilizado para referir a las hazañas del hijo de Zeus (cf. Il. 8.363; Od. 11.622).
} 
desgracias de la casa (v. 597), y al dolor que experimenta Heracles por su última "hazaña" contra sus hijos y su esposa

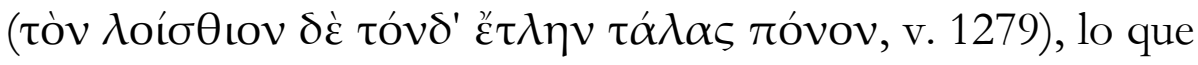
reduce la magnitud de los proezas anteriores a la luz del nuevo esfuerzo a sobrellevar. El valor de este término es intercambiable en la tragedia con $\mu o ́ \chi \theta o s / \mu o \chi \theta \varepsilon ́ \omega$ (vv. 355$356,698,830,1251,1270$ ), que igualmente se usa para referir a las acciones y a los sufrimientos de Heracles, parangonables entre sí por su extraordinariedad. Así, Anfitrión llama a su hijo тoגútovos ('muy doloroso', 'muy esforzado', v. 1190), y más

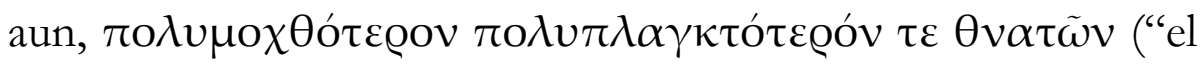
más esforzado y extraviado de los mortales”, v. 1197), refiriendo a su capacidad superlativa de dolor. ${ }^{15} \mathrm{Y}$ el mensajero asegura, al final de su relato, no conocer a alguien más desdichado o con más capacidad de soportar el dolor (oủ

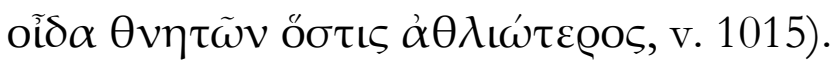

La cadencia de la locura, su pulso rítmico, está determinado en la obra por las dos emociones que ya los textos médicos

${ }^{15}$ Las adjetivaciones del v. 1197 son realmente extraordinarias, no solo por su carácter inusitado, que las convierte en hápax, sino porque la magnitud de la ponderación alcanza a la extensión misma de las palabras en el verso. La polisemia, además, hace

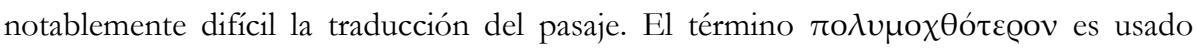
únicamente en esta ocasión en la tragedia, aunque en grado positivo hallamos otros ocho ejemplos del mismo adjetivo en Eurípides, generalmente para referir a la dolorosa condición humana (Hec. 95, El. 1330, Fen. 784, 800, IA 1330 [2], fr. 638a.1 K, fr. 916.1 $\mathrm{K})$. No está, sin embargo, testimoniado en Esquilo, y en Sófocles hallamos un solo

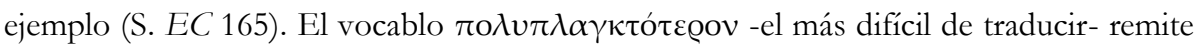
a la idea de la errancia o vagabundeo que, como ha demostrado R. Padel (1997 [1995]), es una de las imágenes de la locura trágica (la misma imagen está presente en $\mu \alpha \iota v o \mu \varepsilon \dot{v \omega} \pi \iota \tau \dot{\lambda} \omega \omega \pi \lambda \alpha \gamma \chi \theta \varepsilon i \varsigma$, v. 1187). El compuesto es único en Eurípides, y de matriz esquílea, ya que es el que se aplica a la locura de Ío (Esq. Sup. 572).

$N^{\circ}$ 5. Primer Semestre de 2016 
reconocían asociadas a la llamada "enfermedad sagrada" (cf. Hipócrates: Sobre la enfermedad sagrada): el miedo y la vergüenza. El primero preanuncia el clima de la segunda parte de la tragedia, con la referencia del coro de ancianos de Tebas a la aparición del phásma de Lisa (v. 816). Ciertamente los estados de pánico y terror son síntomas estándar del delirio y la manía, pero en Heracles, estas emociones están reservadas en principio a los espectadores de la locura, no a su víctima (cf. vv. 950, 971). El tiempo del dolor, en cambio, es el tiempo de la vergüenza, expresada en los términos $\alpha \grave{i} \delta \omega \varsigma$ y $\alpha \mathbf{i} \sigma \chi v \dot{v} v \omega{ }^{16}$ Heracles lamenta la contaminación que como homicida representa para la comunidad social (vv. 1155-1162), y su preocupación por la mancha que comporta lo lleva a pensar como única salida posible el suicidio cuando su padre le recuerda las hazañas que ha realizado. Solo la llegada de Teseo -una suerte de deus ex machina humano (Stafford, 2012, p. 89)logrará impedirlo. Pero esta llegada es también la que activa el profundo sentimiento de vergüenza por sus hechos, al punto de querer ocultar el rostro tras el peplo (vv. 1159-1160, 11981201). ${ }^{17} \quad \mathrm{Si}$ la emoción se inscribe en el cuerpo (Theodoropoulou, 2012, p. 461), y este habla elocuentemente por sus gestos, el gesto del ocultamiento, aquí como en Orestes,

\footnotetext{
${ }^{16}$ La complementariedad de las esferas de significación de ambos términos en la lengua griega ha sido desarrollada por D. Cairns en Aidôs: The Psychology and Ethics of Honour and Shame in Ancient Greek Literature (Cairns, 1993).

${ }^{17} \mathrm{El}$ uso de aidós/aischýno en estos dos pasajes deja en claro la complementariedad del

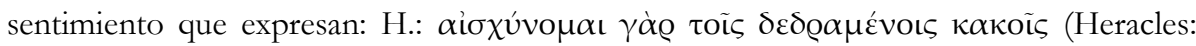

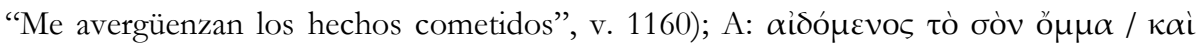

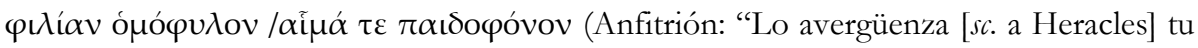
rostro y tu amistad hermana, y la sangre filicida”, vv. 1199-1201).
} 
adquiere un valor significativo. El tono emocional de la escena con Teseo está determinado por el dolor de la vergüenza, la conciencia de un míasma al que el rey ateniense, sin embargo, no le teme, y para quien ni siquiera existe (v. 1232). ${ }^{18}$

Al comienzo de la tragedia, cuando aún no es posible predecir la dimensión de los sufrimientos que se avecinan, Anfitrión afirma la capacidad del tiempo de curar, de proporcionar un remedio (äk $\rceil,$ v. 93) a los males. Pero aunque la aparición y el rescate de Teseo fuerzan en los anuncios del éxodo a proyectar las esperanzas en el nuevo tiempo que aguarda a Heracles en Atenas, para la magnitud del dolor de

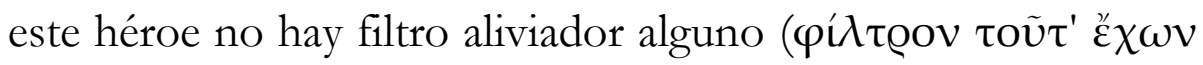

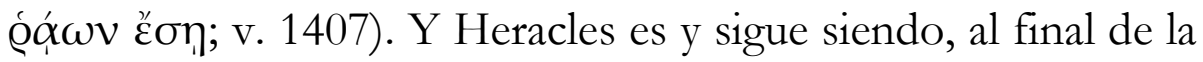

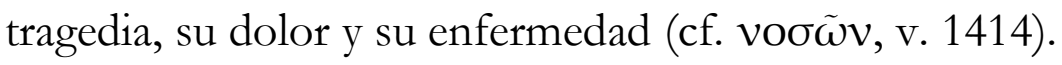

¿Qué destino espera, entonces, a la pólis y al ôkkos? Aunque la caótica situación de Tebas es olvidada completamente después de la muerte de Lico, la ciudad vuelve al centro del discurso trágico en la escena final, ahora desdoblada en su contramodelo, Atenas. Es allí que Heracles, por mediación de Teseo, será purificado y recibirá los honores de varón

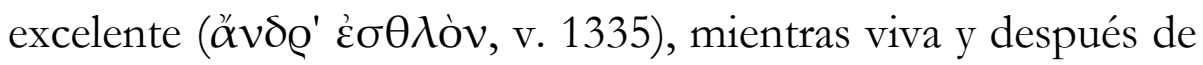
muerto. Pero en Tebas, en el escenario de Tebas, solo queda el dolor, tal como expresa la recurrencia del verbo $\pi \varepsilon v \theta \varepsilon \dot{c} \omega / \sigma u \mu \tau \varepsilon v \theta \varepsilon \dot{\omega} \omega$ ('estar en duelo'/ 'Condolerse') en los vv.

${ }^{18}$ El estudio de R. Parker, central para la comprensión de la noción religiosa arcaica de míasma, expone los ejemplos de Heracles y Orestes como expresión de "those situations where the infectiousness of pollution is either explicitly denied or nobly disregarded in favour of a higher ideal" (Parker, 1983, p. 309).

$N^{\circ}$ 5. Primer Semestre de 2016 
1390 y 1391. Anfitrión ha quedado sin descendientes, y Heracles debe marcharse, sin poder ejercer los deberes y derechos de la philía: sin enterrar a sus hijos, sin poder garantizar el entierro a su padre. El silencio sobre el futuro político de la ciudad de Tebas y sobre la continuidad del ôkos de Anfitrión y de Heracles solo perpetúa el dolor en el momento de la pérdida. ${ }^{19}$

\section{Orestes, ¿el dolor de la locura o la locura de dolor?}

En Orestes, la enfermedad del protagonista se enmarca en las consecuencias de la venganza del hijo de Agamenón, cuyas repercusiones comprometen tanto la salud del propio Orestes como el destino de la familia Atrida y de la misma pólis argiva. Elecciones significativas de esta interrelación entre el destino del héroe, su génos y la pólis son dos de las novedades en la presentación euripidea del mito. Por un lado, como ha destacado entre otros Enrico Medda, la elección de Argos como el nuevo escenario político del drama (Medda, 1999): Orestes no ha abandonado su ciudad tras el matricidio, sino que, sumido en la postración derivada de su enfermedad, permanece allí después de seis días de la muerte de Clitemnestra, asistido por su hermana Electra a la espera de la sentencia definitiva de la ciudad. El nuevo escenario espaciotemporal elegido por Eurípides conlleva la sustitución del

19 En tal sentido resultan significativas las palabras finales del coro: "Marchamos, compadecidos y entre muchas lágrimas, pues hemos perdido al más grande de nuestros amigos" (vv. 1427-1428). 
juicio ateniense del Areópago por el juicio de la asamblea de los propios conciudadanos argivos, cuyo momento el poeta hace coincidir con el regreso de Menelao y Helena, y con la llegada del amigo Pílades, extremando de este modo las tensiones entre las relaciones del ôkeos y las obligaciones que crea, y la pólis. Así, la ciudad no permite a Orestes tener el cetro de Agamenón y, excluyéndolo de los espacios sociales (vv. 428-430), se apresta a votar su muerte y la de Electra; pero si ello sucede, el ôkos paterno quedará definitivamente huérfano (v. 664). La otra singularidad de la tragedia es la que se relaciona con la enfermedad de Orestes, la locura, escenificada -y no simplemente descrita- en los momentos precedentes y sucesivos a la crisis, así como en la crisis misma, y caracterizada con la sintomatología de una verdadera enfermedad mental de periódica recurrencia. ${ }^{20}$ De hecho, durante aproximadamente la mitad de la pieza el foco principal es el lecho de enfermo del hijo de Agamenón y las repercusiones de su padecimiento. ${ }^{21}$

\footnotetext{
${ }^{20}$ Esta caracterización singular permite mostrar a Orestes en el estado de devastación y menoscabo de su salud mental que supone la recurrente alternancia de la manía con períodos de cordura, un precario equilibrio y una permanente amenaza de desestabilización que no dan tregua al sufrimiento del héroe, como ha señalado Medda (Medda, 2013, pp. 168-169). La brevedad de la crisis en sí, que en Orestes tiene una extensión menor a la de Heracles, resulta entonces amplificada por el padecimiento que la precede y sigue como parte de una enfermedad que es tanto más amenazante por su posibilidad de reincidencia. La relevancia del tema de la enfermedad en esta tragedia fue destacada tempranamente (Cf. Smith, 1967), y su realismo, como en Heracles, relacionado con las observaciones médicas contemporáneas. Buena parte de la amplia bibliografía sobre el tema es referida por E. Medda (Medda, 2013, p. 167, n. 1).

21 Con excepción del momento de ataque de locura, Orestes permanece en el lecho desde el comienzo del drama hasta el v. 794, en que Pílades lo ayuda a levantarse para dirigirse a la asamblea. La cuestión del lecho y su integración y desaparición de la escenografía en la segunda parte de la pieza (en especial después del cuarto episodio en
} 
Ya en el prólogo, Electra define el mal que perturba a su

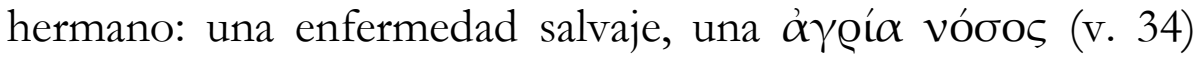
que se confunde, en este punto, con la propia naturaleza mimetizada del paciente (cf. vv. 226, 387). ${ }^{22}$ La enfermedad tiene, pues, en principio, un sentido concreto: la locura de Orestes. Pero en una línea hereditaria que se remonta al mismo Tántalo, esta nósos se inscribe en el catálogo de horrorosos crímenes que conectan a los miembros del génos a través de sucesivas generaciones (cf. vóбov, v. 10). El sino del ổkos Atrida se define así, a partir de esta nósos, por la perpetuación de la desgracia en todos los descendientes, el continuo intercambio de dolor y muerte, como evocan reiteradamente el coro de jóvenes argivas y la misma Electra (vv. 807-843; 971981; 982-1012). El término vóoos y sus derivados (vv. 10, 34, 43, 211, 227, 229, 232, 282, 304, 314, 395, 407, 480, 792, 800,

que Orestes regresa de dicha asamblea) han suscitado respuestas diversas, como sucede con muchos de los aspectos performativos del teatro antiguo. Se ha sostenido tanto el uso del recurso del ekkýklema (Webster, 1967, p. 247), como defendido la flexibilidad de una escenografía convencional que permite entender que la obra se desarrolla en parte dentro del palacio Atrida, en parte delante del mismo (Willink, 1986), o interpretado que el lecho fuera del palacio representa la marginalidad social de Orestes (Bosman, 1993, p. 12). Enrico Medda, a quien remitimos para la bibliografía en torno al tema, discute ampliamente este punto, exponiendo las evidencias textuales que definen la escena inicial como exterior (Medda, 2013, pp. 115-36). De la cuestión escénica se ocupa especial y extensamente también S. Ferrando (Ferrando, 2008).

22 La enfermedad de Orestes es salvaje, y el aspecto mismo de Orestes ha devenido salvaje a partir de ella. Percibida como una fuerza agresiva que ataca al hombre desde el exterior, la enfermedad en su potestad destructiva asume frecuentemente en el corpus trágico la forma de una fiera, como surge aquí de la denominación agría nósos (Cf. S. Tr. 1030, S. Fil. 173, 265-266). Ello responde a un imaginario arcaico que no es extraño a la nueva medicina racional (Jouanna, 1988), aunque haya autores que atribuyan un valor plenamente técnico a la expresión aludida (Garzya, 1992, pp. 25-26). 
$831,881,883,1016)$ y otros términos y expresiones que refieren al campo específico de la locura, como

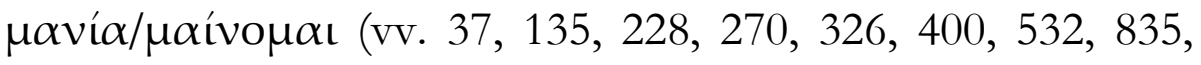
845), $\beta \alpha \kappa \chi \varepsilon v ́ \omega / \alpha ̉ v \alpha \beta \alpha \kappa \chi \varepsilon v ́ \omega ~(338,411,835)$ у $\lambda \dot{v} \sigma \sigma \alpha$ (254, $270,326,401,793,845)$ demuestran la ostensiva presencia de la enfermedad a lo largo de todo el drama. ${ }^{23}$ Su violencia y agresividad aparecen remarcadas no solo por su caracterización salvaje, sino sobre todo por su concepción agonal, evidente en las imágenes del campo atlético y militar que confluyen en torno a la de la enfermedad, y que la revelan en más de un punto como irrupción de una lucha de fuerzas que pugnan en el interior del mismo Orestes. ${ }^{24}$ Pero no es este el único rasgo que merece señalarse. Si la tragedia ofrece por lo general escasos ejemplos de términos de salud y cura, Orestes resulta excepcional en un doble sentido: por un lado, porque es uno de los pocos dramas en los que la noción de salud o curación

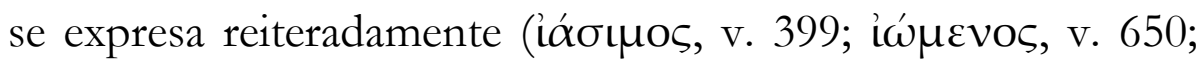

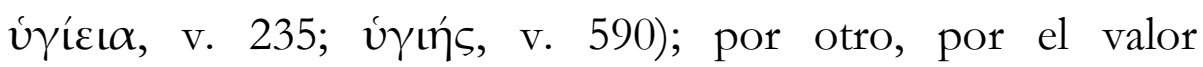
extrañamente positivo al que remiten términos de salud como

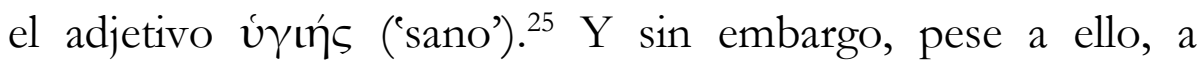

${ }^{23}$ En su reflexión acerca del crimen de Orestes, el coro refiere además al acto con el término patológico científico para la locura: paránoia (v. 824).

24 La concepción agonal de la enfermedad es especialmente notoria en Orestes (Cf. Gambon, 2012). Se trata de una percepción que también comparte la tragedia con la ciencia médica contemporánea (Cf. von Staden, 1990, p. 97).

25 En Eurípides el adjetivo bygiés se usa generalmente en forma negativa, asociado a la mente y con el sentido metafórico de "insensato" (cf. Andr. 448, 952, Hel. 746, Fen. 201, Ba. 262, 948, fr. $493.5 \mathrm{~K}$, fr. $659.5 \mathrm{~N}^{2}$, fr. $824.1 \mathrm{~K}$ ). Más que constituir una metáfora muerta (Cf. Craik, 2001, p. 83), es una metáfora que en nuestra opinión se integra a la propia construcción simbólica del género.

$N^{\circ}$ 5. Primer Semestre de 2016 
diferencia de Heracles, no parece haber cura posible para Orestes, que se muestra desde un comienzo atrapado en la aporía de su mal (v. 232), convertido incluso en una amenaza para la salud de su propia hermana por los cuidados que requiere (vv. 304-305), y para Pílades, que acepta -y no deniega- la posibilidad de contagio estando junto a su amigo (v. 793). Orestes compara en esta situación su destino con el de una ciudad asediada (v. 762). Y cuando la philía de Pílades parece proporcionarle por fin una salida a su situación desesperada -la salida que no le brinda su propio pariente, Menelao- esta toma la forma de una violenta conspiración (vv. 1105-1152), y el phármakon que sugiere Electra (v. 1190) no acarrea una solución ni en el plano político, ni familiar, ni personal. Orestes es un drama que no admite -salvo por mediación divina- la posibilidad de restauración de la salud.

Desde el inicio de la tragedia, el quebranto físico de Orestes es expuesto visiblemente en escena. Aun en los momentos de alivio de su mal, exhausto, la condición de este héroe casi no se diferencia de la muerte (v. 83-84). ${ }^{26}$ Olvidado del alimento y el cuidado de su cuerpo, su respiración, incluso bajo la acción reparadora del sueño, apenas se deja oír (v. 155). Si Electra teme despertarlo es para no avivar un sufrimiento que llena de lágrimas y vergüenza sus momentos de cordura, como de temor sus momentos de locura. Así, si el dolor resulta entronizado en el drama, no es tanto desde las repercusiones

${ }^{26} \mathrm{El}$ coro, en el v. 209, exhorta a Electra a verificar si su hermano no ha muerto sin que ella se percatara. En el v. 879, el mensajero describe la aparición de Orestes en la asamblea con el término $\varphi \alpha ́ \sigma \mu \alpha$ ('aparición'). 
somáticas de la enfermedad, sino especialmente desde las anímicas y emocionales. De ahí que los momentos de locura y de conciencia son de igual modo fuente ininterrumpida de sufrimiento para Orestes.

Ya la sentencia inicial de Electra (vv. 1-3) inserta el dolor del hijo de Agamenón en un esquema universal inexorable, la phýsis del hombre, expresándola en la imagen de la carga, contenida en el término ä $\chi \bigoplus$ o ('pesar', v. 3). Esta imagen, reforzada en el drama por la recurrencia del vocablo ö $\theta \lambda$ เos ('desgraciado', vv. $83,87,121,219,225,295,358,449,952,1166$ ), enfatiza la necesaria capacidad humana de soportar el sufrimiento. El vocativo $\mu$ ć一cos ('mísero', 'desdichado'), de inusitada presencia en este drama, evoca en su desarrollo la condición desgraciada del enfermo (vv. 90, 160, 335, 447, 671, 839, 1029) y de su génos (vv. 192, 207). Electra y el coro llaman la atención sobre lo esforzado de esta condición a la que Orestes ha sido conducido por un dios, utilizando en su lamento la inusual

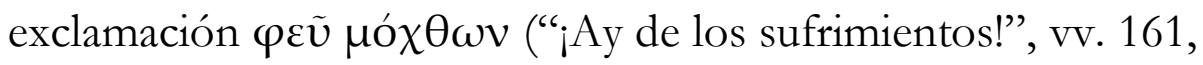
327 , cf. IT 156). ${ }^{27} \mathrm{El}$ término ya estaba presente en Heracles; los contextos de aparición en Orestes (la párodos y el estásimo que preceden y siguen al ataque de locura) permiten pensarlo en este drama en relación a la esfera general de un dolor que es físico y moral a la vez. Hallamos de igual modo en el léxico la preferencia por términos polisémicos como róvos, cuya

${ }^{27}$ Más aun, en el v. 328 el coro, haciendo uso de una etimología del gusto de Eurípides, se refiere a la acción de Orestes con el participio ỏ@e $\chi \theta \varepsilon$ ćs ('extendido', 'alcanzado con la mano'). Orestes, que "ha alcanzado" el oráculo de Apolo, "ha extendido" hasta el extremo sus sufrimientos en el extravío a que lo condena su locura.

$N^{\circ}$ 5. Primer Semestre de 2016 
forma compuesta $\pi$ oגútovos (vv. 175-176, 977, 1012, 1500) у

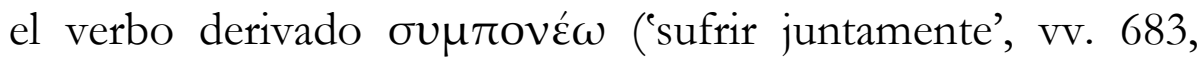
1224) atraviesan el drama. Un hecho significativo es la forma en que, pese a que las desgracias involucran al entorno familiar y a la ciudad misma, los personajes de la tragedia se refieren a ellas repetidamente bajo la forma genérica kaká acompañada del pronombre posesivo que tiene por referente a Orestes, como si el dolor, bajo esa dimensión etiológica que expresa la desgracia, le perteneciese con exclusividad, ínsitamente a él (vv. $85,187,243,381,384,386,393,419,671,683,734,764,768)$.

Como la enfermedad misma, el dolor muestra en esta tragedia su autonomía en su capacidad de agente destructivo.

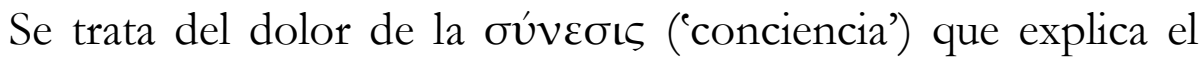
término $\lambda u ́ \pi \eta$ ('pena'), señalado por Smith (1967, p. 297) como "a good medical term from the emotional upset that can bring on disease": ${ }^{28}$

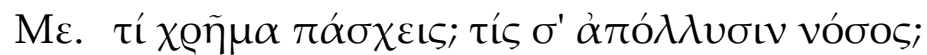

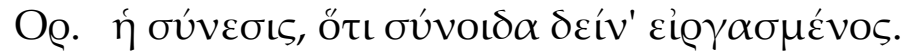

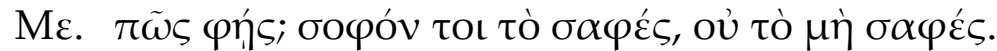

\footnotetext{
${ }^{28}$ En el mismo sentido de referencia al campo emocional, Garzya, en su interpretación

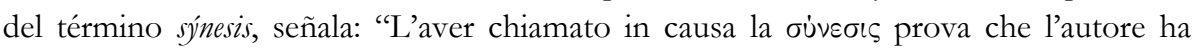
voluto risalire all'origine della patologia descritta rifacendosi a una particolare dottrina della genesi dei processi mentali. L'idea che alla base della coscienza vi fosse una componente emozionale andava certamente facendosi strada per varie vie nella cultura comune già alla fine del V secolo [...]" (Garzya, 1992, p. 31). Se trata de un concepto (y un pasaje textual) cuya significación ha sido ampliamente debatida, y que va de la mano con el nuevo estatuto mental de las Erinias que la escena alucinatoria saca a luz en la tragedia.
} 


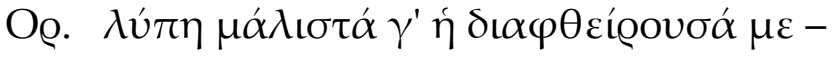

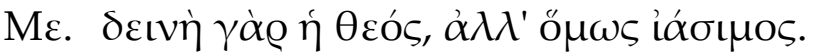

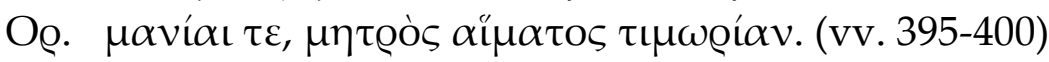

Menelao: ¿Qué cosa sufres? ¿Qué enfermedad te está destruyendo?

Orestes: La conciencia, porque soy consciente de haber hecho cosas terribles.

Menelao: ¿Cómo dices? Sabio es lo claro, no lo que no es claro.

Orestes: Principalmente es la pena la que me destruye...

Menelao: Ciertamente es terrible esta diosa, pero igualmente curable.

Orestes: Y los ataques de locura, castigo de la sangre de mi madre.

Como expresa el pasaje citado, la locura se suma al dolor,

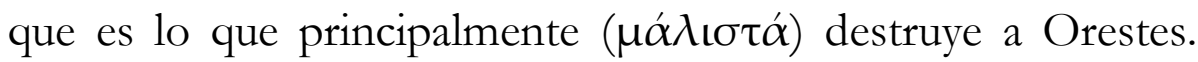
Este sentido de devastación es el que trasunta Orestes en el v. 388 con el verbo $\alpha$ iki $\zeta \varepsilon \tau \alpha \iota$ ('lastimar', 'desfigurar'), al explicar que son las acciones cometidas -el matricidio- las que lo lastiman, proyectando en el estado morboso un doble e indisociable componente psico-físico del dolor. El uso común del verbo $\pi \alpha ́ \alpha \chi \omega$ ('padecer') para referir a la enfermedad y a las Erinias en la escena del interrogatorio de Menelao incursiona en el estatuto ambiguo del síntoma: Orestes padece una enfermedad (v. 395), y padece asimismo en las Erinias el síntoma de esta enfermedad, la alucinación (v. 413). Y como muestra la escena precedente de ataque de locura, cuando el hijo de Agamenón repentinamente cree ver en Electra a una de 
las divinidades vengadoras, es la propia emoción que despierta el nombre de Clitemnestra la que convoca a las diosas, que existen en y por la mente de Orestes. ${ }^{29}$

La autonomía del dolor se manifiesta en esta naturaleza divina que Menelao le reconoce a $\lambda u ́ \pi \eta$ (v. 399) como agente patológico. También, y de modo esencial, en su capacidad de liderar las emociones, conjugando o haciendo alternar los estados de temor y vergüenza. Orestes es presa del terror (vv. $270,297,312$ ) y de visiones igualmente aterrorizantes (v. 407). Cuando está en el lecho, oculta su cuerpo -un gesto "parlante" que confunde el temor y la vergüenza del enfermo-, y aun cuerdo, a pesar del alivio, llora (cf. vv. 42-43). Cuando se recupera de sus crisis, Orestes experimenta vergüenza ante sus

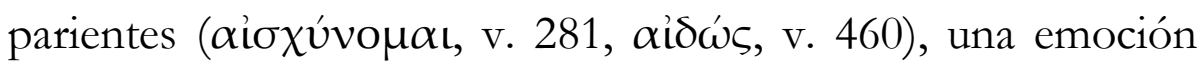
característica de su estado morboso que coincide igualmente con la descrita por los textos médicos (Guardasole, 2000, p. 211). Como el míasma del matricidio, esta emoción resulta en la tragedia "contagiosa", lo que explica que sea Electra aquí la que recurra al gesto de ocultar el rostro tras el peplo, en una actitud que "typically expresses a combination of grief and aidós" (Willink, 1986, p. 132).

Pocas tragedias, según el juicio de E. Hall, requieren un final tan patentemente político como Orestes (Hall, 2010, p. 287); podríamos agregar, considerando la sucesión de acciones

${ }^{29}$ Eurípides inserta así la figura mítica de las Erinias en un nuevo esquema que les otorga el estatuto ambiguo del síntoma. Ellas son la causa del sufrimiento (v. 413) y consecuencia de la manía; son producto de la alucinación, y la alucinación misma (Cf. Holmes, 2010, p. 249). 
dramáticas del éxodo (la muerte de Helena, la captura de Hermíone, la amenaza de destrucción del palacio), un final tan abierta e intrincadamente político y familiar, que pueda garantizar la gobernabilidad de la pólis, la purificación y sanación de Orestes -cuyos crímenes al final de la tragedia se han multiplicado- y la continuidad del génos. Ello solo se vuelve factible en la obra mediante la abrupta aparición de Apolo, en un desenlace que no ha dejado de concitar las opiniones más críticas. Mediante la intervención del dios sanador como deus ex machina, en la escena final del éxodo la profecía proyecta la restauración de la salud de Orestes, así como la salud familiar y social, a un tiempo futuro. Pero este tiempo futuro no oculta su naturaleza ambivalente, y no es posible ignorar, a la luz de los hechos pasados, la precaria estabilidad en que se sostiene: nuevas bodas -las de Electra y Orestes- aseguran la continuidad del ôk os Atrida, los asuntos de la ciudad argiva serán bien reencaminados por Apolo, y tras la purificación de Orestes en el exilio y el juicio absolutorio en Atenas, el héroe podrá gobernar la ciudad (v. 1664). Sin alegar justificativos, el dios se reconoce como instigador del matricidio y promete un futuro restaurador. Aun así, sujeto a las condiciones de la phýsis humana, ese futuro se muestra de una incertidumbre inquietante. Pues fundamentalmente no está exento de la posibilidad de una nueva intervención caprichosa, una irrupción que cambie el curso de los acontecimientos con la misma arbitrariedad con que se dispone Apolo a hacerlo, condenando entonces al hombre a habitar de nuevo su sufrimiento. 
El período clásico proporcionó con el teatro una nueva herramienta cognitiva para procesar las viejas historias del mito, historias de héroes como el matricida Orestes o el filicida Heracles, en quienes la locura deviene su vicisitud fatal. Al hacerlo, acaso como ningún otro género, expuso el dolor como el punto en que se enlazan inextricablemente el cuerpo y la vOz, y buscó nombrarlo bajo sus diversas formas. Nominando el dolor, reconocía sus formas complejas, a la par que se atrevía a trasponer los límites de la ciencia, que desde su nacimiento no ignoró, sin embargo, la ambigüedad del estatuto de este signo. Pero la tragedia fue más allá en la búsqueda de las razones, al conjugar el sufrimiento en todas sus formas en su construcción simbólica. También se mostró menos optimista respecto de la posibilidad de aliviarlo, hecho que no podía dejar de interpelar directamente a una Atenas devastada como la de las postrimerías de la Guerra del Peloponeso. Eurípides, el poeta que más representó y mejor describió los síntomas de la locura, es también quien deja ver de modo elocuente la variedad y la cohesión en el léxico y el imaginario de la enfermedad y del dolor y el modo en que responden a la naturaleza del género, como ilustran los ejemplos de las obras analizadas.

Por ello, frente a la compleja finalidad que ya las poéticas de la Antigüedad procuraron asignarle a la tragedia, frente a las discusiones que han suscitado y continúan suscitando aun hoy las formas y alcances de las funciones implicadas en su proceso catártico (docere, movere, delectare), podríamos concluir coincidiendo una vez más aquí con David Morris- que la paideía más cruda e inexorable del drama consistía (consiste) en 
mostrar que el sufrimiento solo se puede presenciar. Es decir, solo podemos asistir como espectadores al espectáculo del dolor humano, que por eso mismo nos es dado comprender.

\section{Referencias Bibliográficas}

\section{Fuente}

Diggle, J. (Ed.) (1981-94). Euripidis. Fabulae. I-III. Oxford: Oxford University Press.

\section{Bibliografía}

Aguilar, R. M. (2002). "El concepto de normalidad en el Corpus Hippocraticum”. A. Thivel \& A. Zucker (Eds.). Le normal et le pathologique dans la Collection hippocratique, Actes du Xème colloque international hippocratique, Nice, 6-8 Octobre 1999, t. I, Nice: Publications de la Faculté des Lettres, Arts et Sciences Humaines de Nice-Sophia Antipolis, pp. 123-148.

Belfiore, E. S. (2000). Murder among Friends: Violation of philia in Greek Tragedy. New York \& Oxford: Oxford University Press.

Bosman, P. R. (1993). "Pathology of a Guilty Conscience. The Legacy of Euripides' Orestes". AC 36: 11-25.

Brock, R. (2013). Greek Political Imagery from Homer to Aristotle. London: Bloomsbury.

Cairns, D. L. (1993). Aidôs: The Psychology and Ethics of Honour and Shame in Ancient Greek Literature. Oxford: Oxford University Press.

Ciani, M. G. (1974). "Lessico e funzione della follia nella tragedia greca”. Boll. Ist. Fil. Gr 1: 70-110. 
Craik, E. (2001). "Medical Reference in Euripides”. BICS 45: 8195.

Duchemin, J. (1967). "Le Personnage de Lyssa dans l’ Héraclès Furieux d'Euripide". REG 80: 130-139.

Ferrando, S. (2008). “Considerazioni sceniche sull' Oreste folle di Euripide”. Maia 60.1: 34-39.

Gambon, L. (2009). La institución imaginaria del oikos en la tragedia de Eurípides. Bahía Blanca: Ediuns.

Gambon, L. (2012). "El imaginario trágico de la locura: la metáfora agonal y la caracterización de la enfermedad en Orestes de Eurípides”. G. N. Hamamé \& M. C. Schamun (Eds.). Actas del VI Coloquio Internacional Agón: Competencia y Cooperación. De la antigua Grecia a la actualidad. Homenaje a Ana María González de Tobia. La Plata, junio de $2012 . \quad$ Web. http://coloquiointernacionalceh.fahce.unlp.edu.ar/6ciceh

Gambon, L. (2016). "Enfermedad y marginalidad en el drama: construyendo la gramática de la locura". V. Gastaldi, C. Fernández \& G. De Santis (Coords.). Imaginarios de la integración y la marginalidad en el drama griego ático. Bahía Blanca: Ediuns, pp. 131-165.

García Novo, E. (1981). "Simetría estructural. Importancia de la escena en la tragedia griega". Habis 12: 43-57.

Garzya, A. (1992). "Synesis come malattia: Euripide e Ippocrate”. Vichiana 3: 25-32.

Gregory, J. (1997). Euripides and the Instruction of the Athenians. Ann Arbor: The University of Michigan Press.

Griffiths, E. (2006). Euripides: Heracles. London: Duckworth.

Guardasole, A. (2000). Tragedia e medicina nell'Atene del $V$ secolo A.C. Napoli: M. D’Auria Editore. 
Hall, E. (2010). Greek Tragedy: Suffering under the Sun. Oxford: Oxford University Press.

Holmes, B. (2010). The Symptom and the Subject: The Emergence of the Physical Body in Ancient Greece. Princeton: PUP.

Hope, V. M. \& Marshall, E. (Eds.). (2000). Death and Disease in the Ancient City. London \& New York: Routledge.

Jouanna, J. (1988). "La maladie sauvage dans la Collection Hippocratique et la tragédie grecque". Metis 3.1: 343-36o.

Kosak, J. C. (2004). Heroic Measures: Hippocratic Medicine in the Making of Euripidean Tragedy. Leiden: Brill.

LaCourse Munteanu, D. (2012). Tragic Pathos: Pity and Fear in Greek Philosophy and Tragedy. Cambridge: Cambridge University Press.

Medda, E. (1999). "La casa e la città: spazio scenico e spazio drammatico nell'Oreste di Euripide". SIFC 17.1: 12-65.

Medda, E. (2001). Euripide: Oreste. Milano: BUR.

Medda, E. (2013). La saggezza dell'illusione: Studi sul teatro greco. Pisa: Edizioni Ets.

Mitchell-Boyask, R. (2008). Plague and the Athenian Imagination: Drama, History and the Cult of Asclepius. Cambridge: Cambridge University Press.

Morris, D. (1994 [1991]). La cultura del dolor. Santiago de Chile: Andrés Bello.

Padel, R. (1992). In and Out of the Mind: Greek Images of the Tragic Self. Princeton: PUP.

Padel, R. (1997 [1995]). A quien un dios quiere destruir, antes lo enloquece. Elementos de la locura griega y trágica. Buenos Aires: Manantial. 
Parker, R. (1983). Miasma, Pollution and Purification in Early Greek Religion. Oxford: Clarendon Press.

Perdicoyianni-Paléologou, H. (2009a). "The vocabulary of madness from Homer to Hippocrates, Part I: the verbal group of mainomai”. History of Psychiatry 20.3: 311-339.

Perdicoyianni-Paléologou, H. (2009b). "The vocabulary of madness from Homer to Hippocrates, Part II: the verbal group of bakcheúo and the noun lýssa". History of Psychiatry 20.4: 457-467.

Sanz Morales, M. \& Librán Moreno, M. (2008). "El contraste como procedimiento compositivo en el Heracles de Eurípides”. QUCC 88.1: 59-78.

Schamun, M. C. (1995). "Significaciones del efecto de sparagmós en Orestes de Eurípides”. Synthesis 2: 53-65.

Schironi, F. (2010). "Technical Languages: Science and Medicine". E. J. Bakker (Ed.). A Companion to the Ancient Greek Language. Londres: Blackwell Pub., pp. 338-353.

Smith, W. D. (1967). "Disease in Euripides' Orestes". Hermes 95: 291-307.

Stafford, E. (2012). Herakles. London \& New York: Routledge.

Theodorou, Z. (1993). "Subject to Emotion. Exploring Madness in Orestes". CQ 43.1: 32-46.

Theodoropoulou, M. (2012). "The emotion seeks to be expressed". A. Chaniotis (Ed.) Unveiling Emotions. Sources and Methods for the Study of Emotions in the Greek World. Stuttgart: Franz Steiner Verlag, pp. 433-468.

Villard, L. (2006). "Vocabulaire et représentation de la douleur dans la Collection hippocratique". F. Prost \& J. Wilgaux (Dirs.). Penser et représenter le corps dans l'Antiquité. Rennes: Presses universitaires de Rennes, pp. 61-78. 
von Staden, H. (1990). "Incurability and hopelessness: the Hippocratic Corpus". P. Potter, G. Maloney \& J. Desautels (Eds.). La Maladie et les maladies dans la Collection hippocratique: Actes $d u$ VIe Colloque international hippocratique, Quebec, 1987. Québec: Les Éditions du Sphinx, pp. 75-112.

Webster, T. B. L. (1967). The Tragedies of Euripides. London: Methuen.

Willink, C.W. (Ed.). (1986). Euripides: Orestes. Oxford: Oxford University Press.

Wright, M. (2008). Euripides: Orestes. London: Duckworth.

Zeitlin, F. (1990). "Thebes: Theater of Self and Society in Athenian Drama". J. J. Winkler \& F. Zeitlin (Eds.). Nothing to do with Dionysos?: Athenian Drama in its Social Context. Princeton: Princeton University Press, pp. 130-167. 